\title{
Assessment of habitat and survey criteria for the great crested newt (Triturus cristatus) in Scotland: a case study on a translocated population
}

\author{
Lynsey R. Harper (D) · J. Roger Downie - Deborah C. McNeill
}

Received: 28 December 2017/Revised: 22 August 2018/Accepted: 9 October 2018/Published online: 24 October 2018

(C) The Author(s) 2018

\begin{abstract}
The great crested newt Triturus cristatus has declined across its range due to habitat loss, motivating research into biotic and abiotic species determinants. However, research has focused on populations in England and mainland Europe. We examined habitat and survey criteria for great crested newts in Scotland, with focus on a large, translocated population. Adult counts throughout the breeding season were obtained annually using torchlight surveys, and Habitat Suitability Index (HSI) assessed at created ponds $(N=24)$ in 2006 (immediately posttranslocation) and 2015 (9 years post-translocation). In 2006, 'best case' HSI scores were calculated to predict habitat suitability should great crested newts have unrestricted access to terrestrial habitat. Abiotic criteria included in and omitted from current great
\end{abstract}

Handling editor: Lee B. Kats

Electronic supplementary material The online version of this article (https://doi.org/10.1007/s10750-018-3796-4) contains supplementary material, which is available to authorized users.

L. R. Harper $(\square)$

Biology Department, School of Environmental Sciences, University of Hull, Kingston upon Hull HU6 7RX, UK e-mail: lynsey.harper2@gmail.com

L. R. Harper · J. R. Downie · D. C. McNeill School of Life Sciences, College of Veterinary, Medical and Life Sciences, University of Glasgow,

Glasgow G12 8QQ, UK crested newt survey guidelines were assessed using data recorded in 2015. Some ponds had improved HSI scores in 2015, but overall failure to meet predicted scores suggests management is needed to improve habitat suitability. Great crested newt activity was positively associated with moon visibility and phase, air temperature, and $\mathrm{pH}$, but negatively correlated with water clarity. Importantly, our results indicate there are abiotic determinants specific to Scottish great crested newts. Principally, survey temperature thresholds should be lowered to enable accurate census of Scottish populations.

Keywords Amphibian - Conservation - Monitoring · Ponds · Predictors $\cdot$ Salamander

\section{Introduction}

Biodiversity monitoring is crucial to understand changes in species abundance and inform strategies for effective conservation and management (Sala et al., 2000; Butchart et al., 2010; Bowler et al., 2017). Amphibians are one of the most globally threatened groups partly due to loss of and changes to their aquatic and terrestrial habitat (Denoël \& Ficetola, 2008), with one-third of species estimated as threatened with extinction (Stuart et al., 2004). Amphibian habitat has become degraded, fragmented, or lost due 
to anthropogenic activity (primarily urbanisation and land use change), and populations have been affected by introduced species, disease, and climate change (Beebee \& Griffiths, 2005). Furthermore, threats to some species may be underestimated due to data deficiency (Howard \& Bickford, 2014).

In the UK, decline of the great crested newt Triturus cristatus (Laurenti, 1768) has been observed in response to pond loss and degradation, attributable to urban development, agricultural intensification, and introduction of fish species (Gent, 2001; Edgar et al., 2005; Edgar \& Bird, 2006; O’Brien, 2016). Newt larvae in particular require open water, increasing susceptibility to fish predation (Langton et al., 2001). Loss of ponds impacts great crested newt breeding success as adults are philopatric to breeding ponds and unable to migrate long distances to new ponds (Edgar \& Bird, 2006; Beebee, 2015), with maximum recorded distance of $1.6 \mathrm{~km}$ (Haubrock \& Altrichter, 2016). Breeding success is further hampered by a chromosomal defect causing 50\% egg abortion (Macgregor, 1995). Moreover, great crested newts have distinct habitat requirements and infrequently occupy urban or garden ponds in the UK as opposed to the common frog (Rana temporaria Linnaeus, 1758) and smaller newts (Oldham et al., 2000; Langton et al., 2001; Beebee, 2015). The effect of anthropogenic stressors in combination with species ecology has produced small, localised, and fragmented populations of great crested newts in the UK (O'Brien et al., 2015).

In response to declines, great crested newt populations are protected by UK and European legislation at all life stages (McNeill et al., 2012; Lewis et al., 2017). This legislation states that it is an offence to kill, injure, or take great crested newt individuals. Disturbance is prohibited, and breeding sites and hibernacula are protected (McNeill et al., 2012; Lewis et al., 2017). The conservation status of the great crested newt necessitates pond restoration and creation alongside protection of current breeding ponds (Gustafson et al., 2009). However, effective conservation and management can only be informed by research on species ecology and habitat requirements, in particular the biotic and abiotic variables that may influence the distribution and abundance of populations (Denoël \& Ficetola, 2008; Gustafson et al. 2009; Vuorio et al., 2013).
Great crested newt occupancy and abundance are substantially influenced by air and water temperature (Griffiths \& Inns, 1998; Gustafson et al., 2009; Kröpfli et al., 2010), pH and conductivity (Beebee, 1985; Stumpel \& van der Voet, 1998; Skei et al., 2006; Gustafson et al., 2009), presence of fish (McLee \& Scaife, 1992; Ficetola \& De Bernardi, 2004; Hartel et al., 2010; Denoël et al., 2013), lunar activity (Deeming, 2008; Grant et al., 2009; Grant et al., 2012), surrounding terrestrial habitat (Joly et al., 2001; Denoël \& Ficetola, 2008; Gustafson et al., 2011; Denoël et al., 2013; Vuorio et al., 2013; Miró et al., 2016), and overall habitat suitability (Oldham et al., 2000). These relationships vary widely across studies but generally, great crested newts are more likely to inhabit ponds that are permanent or rarely dry, and within reach of 3-10 ponds per $\mathrm{km}^{2}$. Ponds should possess a surface area of $400-800 \mathrm{~m}^{2}$, good water quality, 60-80\% macrophyte cover, up to $60 \%$ shoreline shade, and good surrounding terrestrial habitat (i.e. semi-natural environments, such as rough grassland, scrub or woodland, and also brownfield sites and low intensity farmland) covering more than $75 \%$ of available area (Oldham et al., 2000).

Identified great crested newt associations have largely been based on studies of populations in continental Europe, and in the UK centred in England where the species has widespread distribution (Lewis et al., 2017). Conversely, the species is uncommon in Scotland, with a restricted distribution in the south and a distinct population in the Highlands (O'Brien et al., 2015). The majority of Scottish populations are small despite being present in around 200 locations (O'Brien, 2016). The largest Scottish population of great crested newts is believed to reside at Gartcosh, North Lanarkshire. With 1,012 adults counted by trapping over the period 2004-2006, this population was estimated to represent 9-29\% of the overall Scottish population (McNeill, 2010). This significant population was also the first in Scotland to undergo conservation-based translocation, from 2004 to 2006, to the specially created Gartcosh Nature Reserve (GNR) after being threatened by industrial development during the 1990s (McNeill et al., 2012; Harper et al., 2017). The most recent post-translocation assessment found the population had prospered on the whole; however, two subpopulations had declined, indicating some ponds were less suitable than others (Harper et al., 2017). Only a handful of studies have 
examined habitat requirements of the great crested newt in Scotland (McNeill, 2010; Miró et al., 2016; O'Brien et al., 2017), but this is a major knowledge gap that must be urgently addressed.

We assessed habitat and survey criteria for the great crested newt in Scotland, using the translocated population at Gartcosh as a case study. First, we used the Habitat Suitability Index (HSI), employed as standard in great crested newt surveys (Oldham et al., 2000; ARG-UK, 2010), to compare created pond habitat within GNR for great crested newts immediately following and 9 years after translocation. We anticipated habitat suitability would improve over time as a result of more available terrestrial habitat and greater connectivity between subpopulations within GNR. Secondly, we assessed survey criteria for great crested newts in Scotland. We examined whether the Gartcosh population exhibited the expected relationship with the HSI, and the response of this population to reported abiotic determinants that inform current survey guidelines. Great crested newt adult counts were anticipated to increase as HSI score increased. Higher adult counts were expected at higher temperature and $\mathrm{pH}$, lower conductivity, and around the new moon. Our results will guide future monitoring of the great crested newt, enable more accurate census of populations, and influence pond management in Scotland, with potential applications at similar latitudes across Europe.

\section{Materials and methods}

Study site and data collection

During 2004-2006, a population of great crested newts was relocated from Gartcosh Industrial Site to GNR (McNeill, 2010; McNeill et al., 2012). The licence granted by the Scottish Executive required 10 years of post-translocation monitoring, which was carried out by Heritage Environmental Ltd (2006-2009), URS Corporation Ltd (2010-2012), and Acorna Associates Ltd (2013). The translocation was also the focus of an intensive research project undertaken by McNeill (2006-2010), funded by Scottish Natural Heritage (SNH) in consultation with North Lanarkshire Council (NLC) (McNeill, 2010). In 2015, post-translocation monitoring was completed by Harper (Harper et al., 2017).
GNR contains 24 ponds distributed across four distinct zones: Bothlin Burn (BB), Stepping Stone (SS), Garnqueen Hill (GQ) and Railway Junction (RJ) (Fig. 1). Following creation of the GNR, amphibian proof perimeter fences surrounded each zone. The purpose of the fencing was to prevent newts returning to their original location on the industrial site, but it also had the effect of preventing dispersal between zones and reducing available terrestrial habitat (McNeill, 2010). In 2006, GNR aquatic and terrestrial habitat suitability was evaluated for great crested newts using the HSI score (McNeill, 2010). Ten criteria contribute to this scoring system: location, pond area, pond age, water quality, perimeter shading, presence of waterfowl, presence of fish, number of ponds within $1 \mathrm{~km}$ radius, terrestrial habitat quality and percentage of macrophyte cover (Oldham et al., 2000). From these criteria, a decimal score is calculated to represent habitat suitability $(0=$ unsuitable habitat, $1=$ optimal habitat).

Two HSI scores were calculated for each pond by McNeill. The first score ('HSI 2006') evaluated pond conditions in summer 2006, when perimeter fencing was intact. The second score ('HSI Best Case') was calculated assuming removal of the fencing, resulting in access to maximum available terrestrial habitat and maximum pond surface area determined by maximum winter draw down. All other HSI metrics were estimated according to standard guidelines (Oldham et al., 2000; ARG-UK, 2010). Fences surrounding pond perimeters were removed in May 2011. In spring 2015, Harper determined 'HSI 2015' scores per pond based on maximum terrestrial habitat available postfence removal and pond surface area at time of survey (Online Resource 1).

Each pond was surveyed for great crested newts and other amphibians by torchlight five times during March-May in 2006 and 2015. Surveys started 30 min after dusk on calm, dry nights with temperatures exceeding $5^{\circ} \mathrm{C}$, adhering to current great crested newt survey guidelines (Langton et al., 2001; Sewell et al., 2013). SNH guidance was followed to ensure welfare of great crested newts and non-target species. ARG-UK (2008) advice for disease and non-native species control measures was adhered to. Order of ponds surveyed during each visit was randomised. Two observers walked slowly around each pond with a Cluson 1,000,000 candlepower torch, checking for all adult amphibians in the torch beam at $1 \mathrm{~m}$ intervals, 


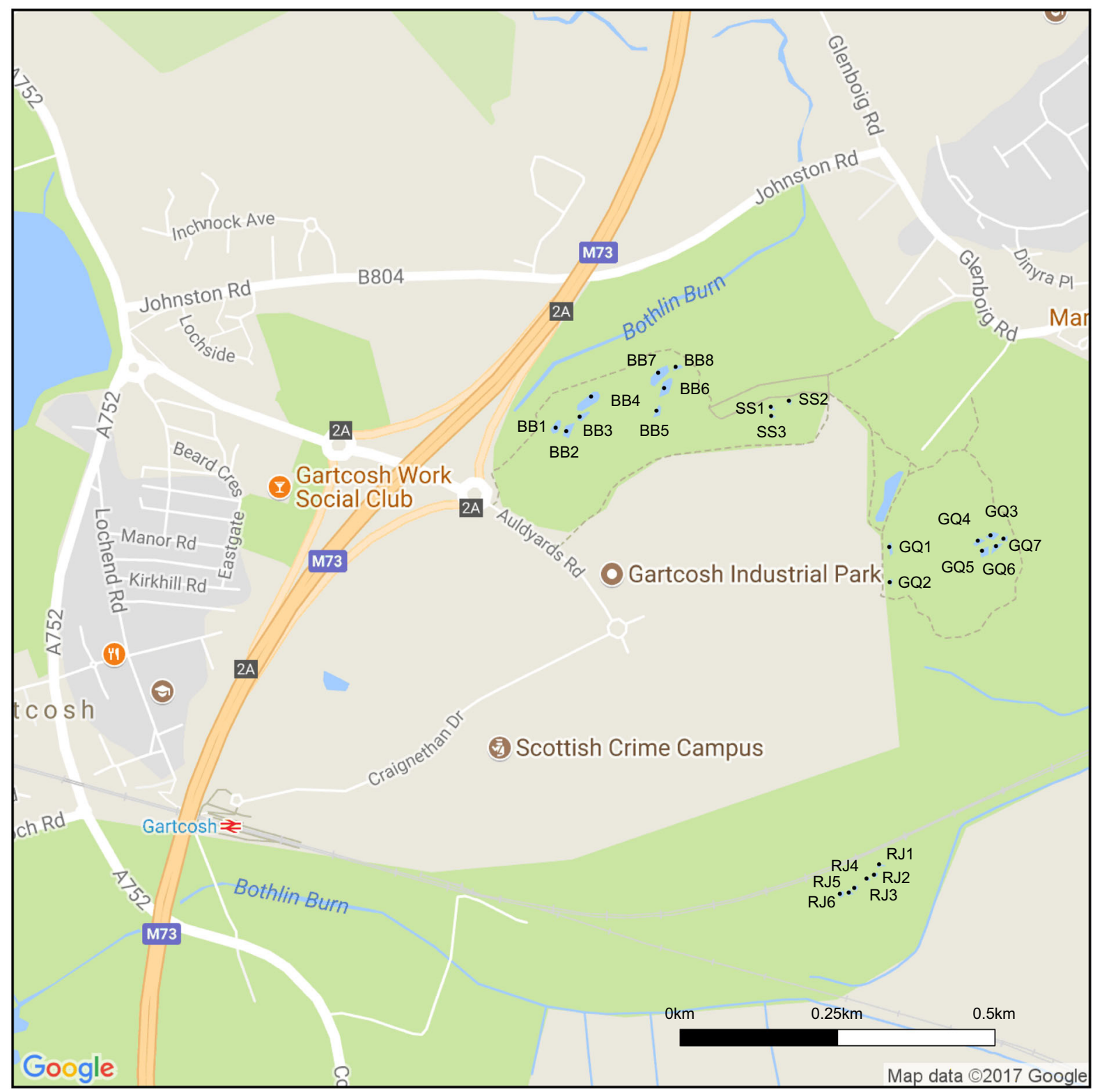

Fig. 1 Google Map of GNR showing all four zones: Bothlin Burn, Stepping Stone, Garnqueen Hill and Railway Junction. Bothlin Burn consists of eight ponds in two clusters (BB1BB8), whereas Stepping Stone is a small cluster of three ponds

and recording observations (species, number, and sex). Total adult counts were recorded after one full circuit, in accordance with standard methodology (Gent \& Gibson, 1998). Where possible, $100 \%$ of the shoreline was searched.

Each survey visit in 2006 and 2015 was conducted over three nights for the 24 ponds in GNR, so as to
(SS1-SS3). Garnqueen Hill consists of seven ponds in two clusters (GQ1-GQ7) and Railway Junction consists of six ponds (RJ1-RJ6)

exclude variability in great crested newt activity introduced by the time of night when survey was performed (Paterson, 2018). The three nights were intended to be consecutive, but this was occasionally prevented by heavy rain and wind. A complete survey of all 24 ponds took approximately $10 \mathrm{~h}$ over three nights. On each survey visit in 2015 , abiotic variables 
were measured at each pond using a HANNA waterproof tester, including air and water temperature, $\mathrm{pH}$, conductivity and total dissolved solids (TDS). Additionally, date, time, water clarity, extent of daytime rainfall that occurred prior to evening survey, wind, and moon visibility were recorded on each survey visit. The survey form used is available in Online Resource 1. Moon phase data were obtained post hoc from the United States Naval Observatory Astronomical Applications Department.

Data analysis

All data analysis was performed using the statistical programming environment $\mathrm{R}$ version 3.4.3 (R Core Team, 2017). Two ponds (RJ5 and RJ6) were excluded from our analysis as they were dry at the time of HSI assessment in 2006. Although three adults were observed during 2006 at these ponds, they did not constitute great crested newt breeding habitat at that juncture. However, these ponds were wet and suitable for great crested newts in 2015. We provide HSI 2006 scores but do not include these for statistical analysis as they were calculated with fencing intact. HSI Best Case and HSI 2015 were most directly comparable as fences had been removed by 2015 , and HSI Best Case scores assumed removed fencing. Prior to performing the analysis comparing HSI Best Case and HSI 2015, we examined the variance in the difference of means in our data set. The variance was normally distributed (Shapiro-Wilk normality test: $W=0.970, P>0.05$ ), thus HSI Best Case (McNeill, 2010) and HSI 2015 were compared using a paired $t$ test to examine temporal change in habitat suitability.

To assess the application of the HSI at Gartcosh, HSI scores were analysed in separate Generalised Linear Models (GLMs) for relationship to peak and average adult great crested newt counts for each pond in 2015. Peak adult counts are most commonly used by ARG-UK, but may constitute statistical outliers. Akaike's Information Criteria (AIC) was employed to evaluate model fit (Akaike, 1973). A Poisson distribution was initially specified for all models as the response variable was integer count data, but models were overdispersed when tested for overdispersion with the R package 'RVAideMemoire' v 0.9-69 (Hervé, 2015) and a custom function using the Pearson residuals. Overdispersion was resolved with a negative binomial distribution to control for aggregation in the count data and prevent biased parameter estimates (Harrison, 2014). Model fit was assessed using the Hosmer-Lemeshow goodness of fit test within the R package 'ResourceSelection' v0.3-2 (Lele et al., 2014) and by visual examination of fit and residuals.

We then examined effects of abiotic determinants included in and omitted from current survey guidelines on great crested newt activity in the GNR. Collinearity between explanatory variables was assessed using a Spearman's rank pairwise correlation matrix (Fig. 1 in Online Resource 2). High collinearity is suggested to be present between variables that have correlations with magnitudes greater than \pm 0.3 (Booth et al., 1994; Zuur et al., 2009). Collinearity was observed between air temperature and water temperature. As great crested newt survey is recommended on nights where air temperature exceeds $5^{\circ} \mathrm{C}$ (Langton et al., 2001), we chose to retain air temperature for model selection rather than water temperature. Similarly, conductivity and total dissolved solids (TDS) were collinear. Conductivity was retained for model selection as correlations between this abiotic variable and great crested newt counts are more commonly reported in the existing literature (Beebee, 1985; Stumpel \& van der Voet, 1998; Skei et al., 2006). Therefore, water temperature and TDS were removed from the data set so that remaining variables were not highly correlated (Neter et al., 1990; Booth et al., 1994). The variance inflation factors (VIFs) of remaining variables, calculated using the R package 'car' v2.1-6 (Fox \& Weisberg, 2011), indicated that multicollinearity (VIF > 3) was still present between moon visibility and phase. However, it was necessary to model both variables as an interaction term to account for the effect of moon phase when the moon was visible.

The relative importance of the explanatory variables was assessed using a classification tree within the R package 'rpart' v4.1-12 (Therneau et al., 2017). The tree indicated that air temperature was the most important explanatory variable (Fig. 2 in Online Resource 2). A pruning diagram was applied to the data to cross-validate the classification tree and remove unimportant explanatory variables. A tree of 1-19 was optimal, indicating that 1-19 explanatory variables should be retained for statistical analysis (Fig. 3 in Online Resource 2). The remaining explanatory variables were: air temperature, $\mathrm{pH}$, conductivity, water clarity, moon visibility, and moon phase. 
A generalised linear mixed effects model (GLMM) was employed using the R package 'Ime4' v1.1-16 (Bates et al., 2015) to account for dependencies within sites. Dependencies are handled with the introduction of random effects (Pinheiro \& Bates, 2000; McCulloch \& Searle, 2001; Zuur et al., 2009). Since the ponds in this study were nested within the GNR, a mixed model was necessary to account for spatial dependencies between ponds. Furthermore, as surveys at each pond were performed on different nights, date was also treated as a random effect to account for this spread. A negative binomial distribution was specified, and model fit was assessed as for the GLMs. Predictions from the GLMs and GLMM were obtained using inbuilt $\mathrm{R}$ functions (R Core Team, 2017) and model results plotted for evaluation using the $R$ package 'ggplot2' v 2.1.0 (Wickham, 2009). All R scripts and corresponding data have been deposited in a dedicated GitHub repository (https://github.com/ lrharper1/great_crested_newt_habitat_and_survey_ criteria, which has been permanently archived (https://doi.org/10.5281/zenodo.1463690).

\section{Results}

Amphibian counts

Peak adult great crested newt counts for each pond in 2006 and 2015, and average adult counts for each pond in 2015 are provided in Table 1. Adult counts from each survey in 2015 are available in Online Resource 3 (Table S1). Results for other amphibian species are not reported in this paper.

Temporal change in habitat suitability

HSI 2006, HSI 2015, and HSI Best Case scores are presented in Table 1. HSI 2006 ranged between 0.22 and 0.82, excluding RJ5 and RJ6. HSI Best Case predicted a range of 0.62 to 0.87 , and HSI 2015 ranged from 0.62 to 0.86 . Mean HSI score of ponds was significantly lower $\left(t_{21}=-3.552, P<0.001\right)$ in $2015(0.716 \pm 0.064)$ than predicted in 2006 $(0.763 \pm 0.090)$. Ponds in 2015 were therefore less optimal habitat for the great crested newts. Nonetheless, in six cases, the HSI 2015 scores exceeded the corresponding HSI Best Case scores.
HSI and great crested newt adult counts in 2015

In 2015, the ponds at GNR were similar to one another when considering absence of fish and minor impact of waterfowl, but varied in criteria of pond size and water quality. We found no significant correlation between HSI score and peak great crested newt adult counts (GLM: $\quad 1.862 \pm 2.231, \quad Z_{1}=0.835, \quad \chi_{1}^{2}=0.571$, $P=0.450, R^{2}=2.16 \%$ ), or HSI score and average great crested newt adult counts (GLM: $2.052 \pm 2.617$, $\left.Z_{1}=0.784, \quad \chi_{1}^{2}=0.496, \quad P=0.482, \quad R^{2}=1.84 \%\right)$. Great crested newt activity was markedly variable across all 24 ponds, and high adult counts (peak or average) did not always correspond to high HSI score (Fig. 2).

Abiotic determinants of great crested newt adult counts

Great crested newt adult counts for GNR peaked on the first survey in early April 2015 (Table 2). Counts remained high in April and decreased in May. Water temperature of ponds surveyed ranged from 6.2 to $15.6^{\circ} \mathrm{C}$ (median $11.8^{\circ} \mathrm{C}$ ), whilst air temperature ranged from 0.7 to $11.9^{\circ} \mathrm{C}$ (median $7.7^{\circ} \mathrm{C}$ ). Ponds possessed a range of TDS values between 36 and $215 \mathrm{ppm}$ (median $97.5 \mathrm{ppm}$ ), and conductivity ranged between 74 and $628 \mu \mathrm{S} / \mathrm{cm}$ (median $196.5 \mu \mathrm{S} / \mathrm{cm}$ ). Range of water $\mathrm{pH}$ was narrow, from 6.84 to 8.70 (median 7.61). The GLMM explained variation in great crested newt counts with $\mathrm{pH}$, conductivity, water clarity, an interaction term between air temperature and moon visibility, and an interaction term between moon visibility and moon phase (Table 3 ) as fixed effects, in addition to survey date and pond as random effects. The GLMM was not overdispersed $\left(\chi_{104}^{2}=99.375, P=0.610\right)$, and model fit was adequate $\left(\chi_{8}^{2}=-6.158, P=1.000\right)$. The implications of our results for great crested newt monitoring in Scotland are discussed below, but here we provide a brief summary. Fewer adult great crested newts were observed in ponds with medium or turbid water clarity (Fig. 3a), but reduced clarity may also impair observer ability to count individuals. Conversely, great crested newt activity was higher on nights when the waxing gibbous or full moon was visible (Fig. 3b), and on nights when the moon was visible and air temperature was lower (Fig. 3c). Similarly, great crested newt 
Table 1 HSI scores and peak great crested newt adult count for ponds $(N=24)$ in 2006 (immediately after translocation when ponds were new and before removal of amphibian fencing), 2015 (9 years after translocation and after removal of amphibian fencing), and the 'best possible scenario' if amphibian fencing was removed. Average great crested newt adult counts for each pond in 2015 are also given

\begin{tabular}{|c|c|c|c|c|c|c|}
\hline \multirow[t]{2}{*}{ Pond } & \multicolumn{2}{|l|}{2006} & \multicolumn{3}{|l|}{2015} & \multirow{2}{*}{$\begin{array}{l}\text { Best case scenario } \\
\text { HSI score }\end{array}$} \\
\hline & Great crested newt & HSI score & $\begin{array}{l}\text { Great crested newt } \\
\text { (peak) }\end{array}$ & $\begin{array}{l}\text { Great crested newt } \\
\text { (average) }\end{array}$ & HSI score & \\
\hline BB1 & 11 & 0.76 & 22 & 11 & 0.73 & 0.82 \\
\hline BB2 & 7 & 0.76 & 29 & 13 & 0.74 & 0.83 \\
\hline BB3 & 8 & 0.70 & 17 & 9 & 0.73 & 0.78 \\
\hline BB4 & 7 & 0.82 & 28 & 13 & 0.83 & 0.87 \\
\hline BB5 & 6 & 0.75 & 22 & 7 & 0.75 & 0.80 \\
\hline BB6 & 11 & 0.77 & 7 & 3 & 0.86 & 0.82 \\
\hline BB7 & 3 & 0.82 & 32 & 21 & 0.81 & 0.87 \\
\hline BB8 & 0 & 0.71 & 19 & 11 & 0.72 & 0.77 \\
\hline SS1 & 0 & 0.35 & 5 & 1 & 0.68 & 0.64 \\
\hline $\mathrm{SS} 2$ & 1 & 0.22 & 5 & 2 & 0.63 & 0.66 \\
\hline SS3 & 0 & 0.37 & 3 & 1 & 0.65 & 0.67 \\
\hline GQ1 & 0 & 0.74 & 3 & 1 & 0.73 & 0.80 \\
\hline GQ2 & 3 & 0.64 & 15 & 6 & 0.64 & 0.78 \\
\hline GQ3 & 5 & 0.74 & 54 & 33 & 0.76 & 0.81 \\
\hline GQ4 & 5 & 0.79 & 50 & 28 & 0.70 & 0.86 \\
\hline GQ5 & 2 & 0.75 & 41 & 30 & 0.73 & 0.82 \\
\hline GQ6 & 9 & 0.72 & 39 & 20 & 0.73 & 0.78 \\
\hline GQ7 & 1 & 0.77 & 11 & 10 & 0.67 & 0.82 \\
\hline RJ1 & 3 & 0.59 & 26 & 17 & 0.77 & 0.69 \\
\hline $\mathrm{RJ} 2$ & 3 & 0.51 & 27 & 12 & 0.66 & 0.64 \\
\hline RJ3 & 5 & 0.49 & 21 & 11 & 0.62 & 0.63 \\
\hline RJ4 & 3 & 0.52 & 40 & 26 & 0.62 & 0.62 \\
\hline RJ5* & 0 & 0.00 & 47 & 27 & 0.71 & 0.61 \\
\hline RJ6* & 3 & 0.00 & 34 & 26 & 0.75 & 0.63 \\
\hline
\end{tabular}

Peak adult counts were obtained during survey by Heritage Environmental Ltd (HEL) in 2006, and Harper in 2015 . RJ5 and RJ6 had HSI scores of 0 in 2006 as these ponds were dry

activity increased in ponds with higher water $\mathrm{pH}$ (Fig. 3d).

\section{Discussion}

In this study, we have assessed habitat and survey criteria for the largest population of great crested newts in Scotland. We compared habitat suitability between two survey events 9 years apart, evaluated whether the HSI reflected great crested newt adult counts, and assessed abiotic variables that inform current survey guidelines for effects on great crested newt activity. Our results indicate that great crested newts in Scotland may have different habitat and survey requirements to other populations in the UK and further afield in Europe. Therefore, aspects of standard survey guidelines set by regulatory agencies (English Nature, 2001; Langton et al., 2001; Baker et al., 2011; McKinnell et al., 2015), specifically the HSI and air temperature, may not be fully appropriate for great crested newts in Scotland. Our results also indicate the need for quantitative data on environmental variables to be recorded during great crested 


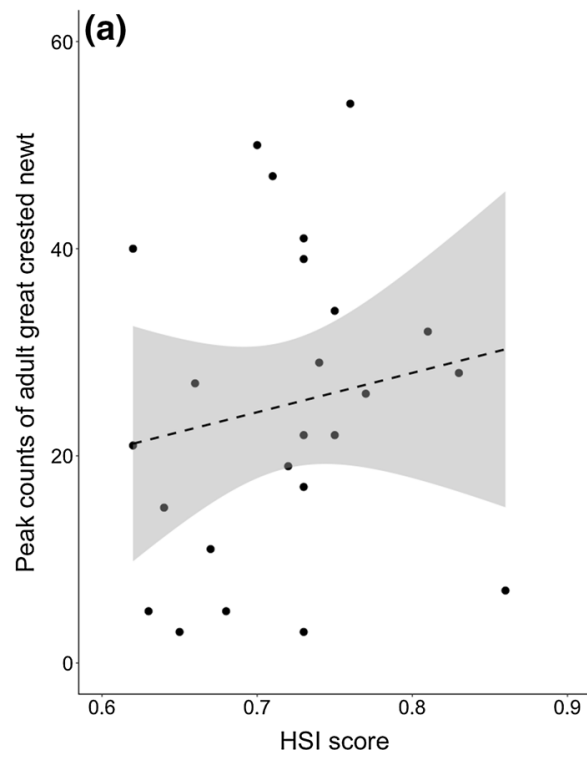

Fig. 2 Relationship between HSI score and adult great crested newt counts (peak and average) across five survey visits, as predicted by the negative binomial GLMs. The $95 \%$ confidence intervals, as calculated using the predicted adult counts and standard error for these predictions, are given for each

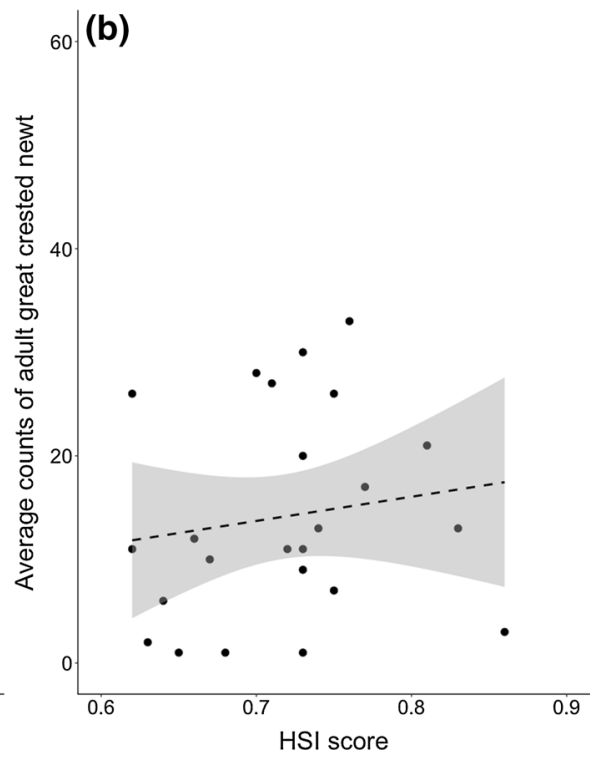

relationship. The observed data (points) are also displayed against the predicted relationships (lines). Both peak (a) and average (b) great crested newt adult counts increased as HSI score increased, but neither relationship was significant

Table 2 Peak great crested newt adult counts for each round of torchlight survey at GNR in 2015

\begin{tabular}{lll}
\hline Survey & Dates & Peak great crested newt adult count \\
\hline 1 & $05 / 04 / 15-07 / 04 / 15$ & 458 \\
2 & $19 / 04 / 15-21 / 04 / 15$ & 420 \\
3 & $29 / 04 / 15-01 / 05 / 15$ & 437 \\
4 & $09 / 05 / 15,11 / 05 / 15-12 / 05 / 15$ & 265 \\
5 & $18 / 05 / 15-19 / 05 / 15,22 / 05 / 15$ & 164 \\
\hline
\end{tabular}

Table 3 Summary of analyses testing for variation in great crested newt adult counts at ponds in GNR $(N=24)$, attributable to explanatory variables

\begin{tabular}{|c|c|c|c|c|}
\hline Model variables & Effect size & Standard error & $\chi^{2}$ & $P$ \\
\hline pH & 0.903 & 0.252 & 12.370 & $<0.001$ \\
\hline Conductivity & 0.001 & 0.001 & 0.273 & 0.273 \\
\hline Water clarity & & & 8.944 & 0.031 \\
\hline Medium & -0.038 & 0.173 & & \\
\hline Turbid & -0.596 & 0.239 & & \\
\hline $\begin{array}{l}\text { Air temperature: moon visible } \\
\text { (yes) }\end{array}$ & 0.305 & 0.086 & 12.512 & $<0.001$ \\
\hline Moon visible: moon phase & & & 7.668 & 0.051 \\
\hline Yes: waxing gibbous & 2.010 & 0.715 & & \\
\hline
\end{tabular}

Effect size and standard error are given for levels of factor explanatory variables. Test statistic is for LRT used. Significant $P$ values $(<0.05)$ are italicized 

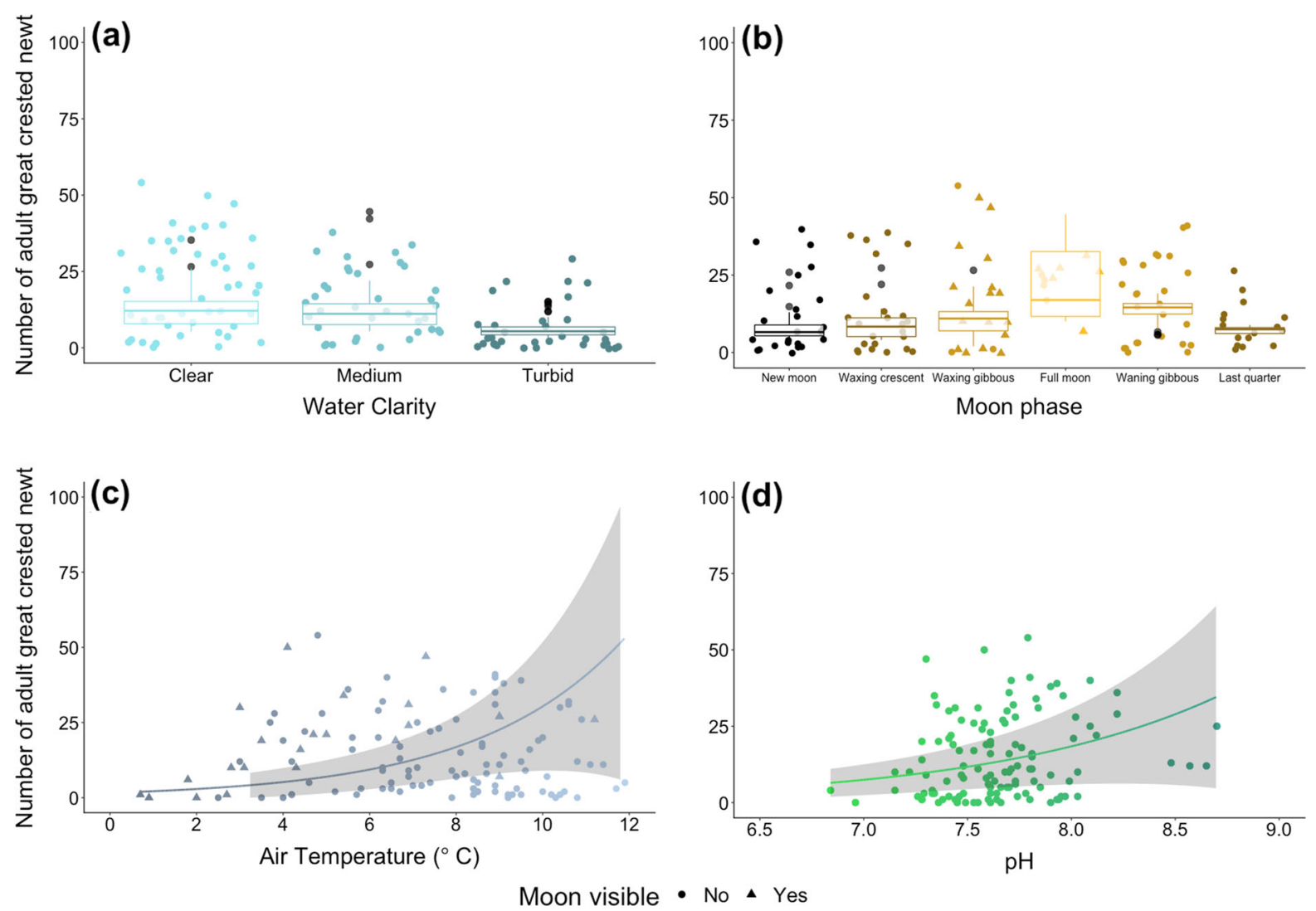

Fig. 3 Relationship between fixed effects and the response variable great crested newt adult counts, as predicted by the negative binomial GLMM. The 95\% confidence intervals, as calculated using the predicted adult counts and standard error for these predictions, are given for each relationship. The observed data (points) are also displayed against the predicted

newt surveys, and continued monitoring of translocated populations.

Some relationships with abiotic variables are shared with other populations in the UK and mainland Europe. Specifically, the negative and positive influences of water clarity and $\mathrm{pH}$ respectively in ponds are consistent with other studies (Stumple \& van der Voet, 1998; Rannap \& Briggs, 2006; Skei et al., 2006; Maletzky et al., 2007; Gustafson et al., 2009; Kröpfli et al., 2010). Yet, others had no effect or appear to be specific to Gartcosh great crested newts. For example, conductivity and TDS were previously identified as great crested newt determinants (Beebee, 1985; Stumpel \& van der Voet, 1998; Skei et al., 2006), but here were not retained by model selection or had no significant effect. However, increased sampling effort over a wider geographical scale may have relationships (boxes/lines). Great crested newt adult counts were lower in ponds with turbid water (a), but greater on nights when the waxing gibbous and full moon were visible (b), the moon was visible and air temperature lower (c), and in ponds with higher water $\mathrm{pH}$ (d)

produced different results. The relationship between great crested newt activity and moonlight was complex, where moon visibility exerted an effect in combination with air temperature and moon phase. Great crested newt activity was higher on nights when the waxing gibbous or full moon was visible and air temperature was lower. Consequently, great crested newt survey guidelines may need to account for variable response to air temperature and moonlight to enable accurate census of populations in Scotland. We recommend that air temperature of $5^{\circ} \mathrm{C}$ specified in current guidelines is reduced to $3-4^{\circ} \mathrm{C}$ to fully capture start of and trends in great crested newt activity throughout the breeding season. We also advocate incorporation of moon visibility and phase during surveys to improve understanding of lunar periodicity in great crested newts. 
Habitat criteria for great crested newts in Scotland

Previously, Oldham et al. (2000) identified the range of HSI scores that could support breeding great crested newt populations as $0.43-0.96$. In 2006, GNR was newly established and amphibian proof perimeter fencing in place. Many of the newly created ponds were small in size and had limited opportunity for dispersal between zones of the GNR-regardless of amphibian fencing. The HSI scores were highly variable (McNeill, 2010) and crucially, the scores of three ponds (SS1-SS3) fell below the minimum HSI score of 0.43 described by Oldham et al. (2000) and a further three ponds (RJ2-RJ4) were not much higher than this. Nonetheless, in 2015 and in the predicted 'best case' scenario, in which maximum potentially available terrestrial habitat was assumed, all ponds fell within the range of 0.43 to 0.96 determined by Oldham et al. (2000). In 2015, six ponds showed improved HSI scores since 2006 whilst one pond remained unchanged. However, 17 ponds in 2015 showed declines in HSI score since 2006, albeit some more severe than others, despite removal of fencing in 2011. Ponds that showed improvement may have benefitted from fencing removal and subsequent opportunity for dispersal within the GNR. However, ponds which showed no change and those that declined indicate that fencing removal alone was inadequate and other aspects of aquatic and terrestrial habitat require management to improve quality. For example, pond hydroperiod, macrophyte cover, terrestrial shading, and connectivity to ponds outwith the GNR.

Critically, the HSI may not be entirely appropriate for Scottish great crested newts. We found no significant relationship between the HSI and great crested newt adult counts (peak or average) in 2015. High HSI score did not always correspond to high adult counts, with some low-scoring ponds containing more great crested newts. While adult counts may have been too coarse to reveal an effect of HSI, our results echo the inconsistency observed across other studies that have examined great crested newts in relation to habitat suitability (Unglaub et al., 2015). It is evident that habitat, or rather estimates of habitat quality or suitability, may not always indicate capability to sustain large populations of great crested newts. HSI may also be a poor predictor of probability of great crested newt occupancy and survival and is perhaps only a reliable tool for assessment of probability of reproduction (Unglaub et al., 2015). This result has implications for the applicability of HSI to assess great crested newt habitat suitability in Scotland, and elsewhere in Europe.

Importantly, our study consisted only of ponds that fell within the range that can support breeding great crested newt populations determined by Oldham et al. (2000). Studies of optimal and non-optimal ponds are necessary to fully understand the habitats great crested newts are capable of utilising and the influence of environmental variables (Gustafson et al., 2009). O'Brien et al. (2017) found that a geographically modified HSI was able to predict great crested newt pond occupancy in Scotland, but whether this also holds true for great crested newt abundance, reproduction, and survival remains untested. Additional information would be required to test this modified HSI, including presence-absence of larvae (probability of reproduction) and capture-mark-recapture records of adult newts (probability of survival) (Unglaub et al., 2015). Indeed, the HSI is not without limitation and should be interpreted with caution (O'Brien et al., 2017). Estimation of criteria used to calculate the HSI score is somewhat subjective and dependent on the scorer (Oldham et al., 2000), which may introduce bias. Furthermore, it has been suggested that the indices comprising this scoring system should be analysed independently as each can affect great crested newt ecology, but may be masked by a high score overall when combined (O'Brien et al., 2017). Consequently, there is a need for detailed examination of this tool in Scotland and broader consideration of alternative methods in the UK and Europe.

Abiotic criteria for great crested newt survey in Scotland

Temperate amphibians have relatively short breeding seasons in spring and a restricted survey timeframe in contrast to tropical amphibians which may breed continuously or at any time throughout the year and away from water (Hartel et al., 2010). Bad weather can prolong breeding but impedes survey effort (Griffiths \& Inns, 1998; Sewell et al., 2013). Surveys are best conducted on warm, calm nights without rain and wind, which cause water perturbation. Daytime rainfall and wind were not retained by model selection in this study, thus these abiotic factors did not influence 
results. Chosen survey conditions were therefore appropriate for great crested newt detection and subsequent estimates of adult density.

Great crested newt survey usually begins in March to avoid reduced detection as water becomes more vegetated and turbid (Langton et al., 2001), and allow more surveys of each pond to achieve the recommended number for $95 \%$ confidence of GCN detection (Kröpfli et al., 2010; Sewell et al., 2013). Survey dates at Gartcosh were variable over the required monitoring period from 2006 to 2013, commencing in March in some years but April in others. Peak adult counts were typically observed in late April, but in 2015 were observed on the first survey in early April. This suggests breeding may have begun in March. Current great crested newt survey guidelines require monitoring to commence at the beginning of March, which we support to fully capture Scottish population trends throughout the breeding season.

Torchlight detection of great crested newts specifically is impaired by changes in vegetation, water clarity, and the end of breeding activity (Maletzky et al., 2007; Kröpfli et al., 2010). Indeed, Rannap \& Briggs (2006) primarily detected great crested newts in ponds with clear water rather than muddy, brown, or algal-green water. Water transparency is important for great crested newt breeding displays and benefits foraging success, but also increases exposure to visually guided predators. Muddy and algal-green water are typical of lower oxygen content, and the acidity of muddy water may impair egg survival. However, Skei et al. (2006) found greater occurrence of great crested newts in slightly acidic water with high humic acid and low electrolytic content. In our study, great crested newt adult counts significantly increased with $\mathrm{pH}$ (6.84-8.70), which corroborates reports of great crested newt in ponds with neutral or slightly alkaline $\mathrm{pH}$ (Stumple \& van der Voet, 1998; Skei et al., 2006; Gustafson et al., 2009). We found statistical support for a seemingly negative effect of water clarity on great crested newt adult counts, similar to previous studies (Rannap \& Briggs, 2006; Maletzky et al., 2007; Kröpfli et al., 2010). However, this could either be a true effect on great crested newt adult counts, or a reflection of observer ability to count more accurately when water is clear. Observer-neutral methods, such as bottle trapping, could disentangle this effect but are more time-consuming and invasive (Sewell et al., 2013).
Torchlight surveys began when air temperature exceeded $5^{\circ} \mathrm{C}$, but some nights in early April 2015 saw unseasonably cold weather (approx. $1^{\circ} \mathrm{C}$ ). Low air and water temperature are commonly reported to affect newt counts through lowered activity, with newts possibly remaining inactive for days, thus impeding detection (Griffiths \& Inns, 1998; Langton et al., 2001; Gustafson et al., 2009; Kröpfli et al., 2010). We did not find a distinct relationship between newt counts and air temperature and instead observed high counts at low and high air temperatures. Kröpfli et al. (2010) also observed lower counts at higher water temperatures (ranging from 6 to $20^{\circ} \mathrm{C}$ ), but Gustafson et al. (2009) recorded an increase in counts as water temperature (ranging from 8.63 to $13.75^{\circ} \mathrm{C}$ ) increased. Closer to home, Paterson (2018) studied the Gartcosh great crested newt population and identified peak adult counts at $3.5^{\circ} \mathrm{C}$ (water temperature $=10.4^{\circ} \mathrm{C}$ ). In our study, the highest adult counts were at air temperatures of 4.1 and $4.8^{\circ} \mathrm{C}$ (water temperature $=9.4$ and $10.1^{\circ} \mathrm{C}$ ), although great crested newt activity at $0.7-3^{\circ} \mathrm{C}$ was much lower (water temperature $=7.5-$ $\left.10.9^{\circ} \mathrm{C}\right)$. Therefore, air temperature specified $\left(5^{\circ} \mathrm{C}\right)$ in current great crested newt survey guidelines (Langton et al., 2001; Sewell et al., 2013) may be too stringent for Scotland as newts may be locally adapted to colder conditions, but research on great crested newt physiology would be required to confirm this.

In our study, air temperature exerted an effect on great crested newt counts in combination with moon visibility. We observed higher great crested newt adult counts on nights with moonlight, which were often cooler $\left(<5^{\circ} \mathrm{C}\right)$. We also found great crested newt activity was higher on nights when the waxing gibbous or full moon was visible. An important consideration is whether moonlight enhanced observer ability to see and count newts. For example, newts may be less disturbed by torchlight when there is a natural source of bright light. However, several species of amphibian have been observed to synchronise breeding behaviour in response to the lunar cycle (Vignolli \& Luiselli, 2013; Vignoli et al., 2014; Kusano et al., 2015). Great crested newt activity is reported to increase around the new moon of the lunar cycle, linked to geomagnetism and higher gravitational pull (Grant et al., 2009). Similarly, higher newt captures in bottle traps were obtained in the waning/new moon phases (Deeming, 2008). Lunar periodicity in newts may be related to reproductive timing rather than navigation, and 
response of newts to lunar cues may be more complex than analysis suggests (Grant et al., 2009). This certainly appears to be the case for great crested newts at Gartcosh, with the intertwined effects of moon visibility, moon phase and air temperature on recorded adult counts. Specific moon phases may have caused newts to be active in spite of undesirable temperature, or perhaps the lunar cycle and weather conditions simply coincided with peak breeding activity. Nonetheless, our results provide support for moon visibility and phase to be incorporated into great crested newt monitoring and research to improve understanding of lunar-related behaviours (Grant et al., 2012). These data could be collected during survey, or retrospectively using lunar calendars as in this study. We did not assess extent of cloud cover, the number of eggs laid, or oviposition site selection behaviour in response to the lunar cycle, but these have been examined in other species of amphibian (Vignoli \& Luiselli, 2013) and would be worthwhile areas of investigation for the great crested newt.

\section{Conclusion}

This Scottish case study both supports and contradicts habitat and survey criteria for the great crested newt derived from other UK and European populations. Critically, not all ponds in GNR seem to be optimal for great crested newt. Although there has been overall improvement on scores since the nature reserve was first established with intact fencing, many ponds did not attain expected habitat suitability if maximum terrestrial habitat was made available by fencing removal. Continued habitat management and conservation effort is required to improve existing ponds (e.g. SS, RJ) within the nature reserve to prevent drying out and to maintain ponds at different stages of succession to provide varied habitat for great crested newts (Oldham et al., 2000; Langton et al., 2001). Addition of new ponds between zones is desirable to maintain and improve connectivity between zones, such as GQ and RJ. This is vital with the forthcoming addition of an access road through the nature reserve to a new housing development (pers. comm. Pardeep Chand \& Kirsty Gray, NLC), which could seriously impact this population. This development alone should imply investment in further monitoring to assess impact of amphibian tunnels (as road mitigation) on migration behaviour (Matos et al., 2017) and effects of pollution from road salt and other chemicals (Duff et al., 2011). Mandatory surveys in March will ensure accurate identification of breeding activity and peak adult counts. Similarly, more informative data on great crested newt activity and breeding behaviour can be obtained if surveys are also performed at lower air temperatures. Further study of lunar periodicity in great crested newts is required in relation to breeding activity and reproduction as well as the interplay between moon visibility and air temperature. Specifically, future studies should aim to record quantitative data on the lunar cycle during great crested newt survey. These adaptations to current guidelines for great crested newt survey will enable more accurate census of populations. However, it is important to note that our results are based on sampling events in 1 year. To confirm the effects of abiotic variables on great crested newt activity, variables must be studied in successive years to ensure consistency. Therefore, continued monitoring of populations is necessary whether funded by local councils or performed by licensed volunteers.

Acknowledgements We should like to express our sincere gratitude to all who assisted with this research. This project would not have been possible without support, information, and dissemination of data from North Lanarkshire Council, especially Pardeep Chand. Adult counts from 2006 were obtained by Heritage Environmental Ltd. We thank Scottish Natural Heritage, Blodwen Lloyd Binns Trust (Glasgow Natural History Society) and University of Glasgow for financial assistance. Dr. Ben Ross, co-supervisor of Deborah's research, and Prof. Barbara Mable, co-supervisor of Lynsey's research, are to be thanked for their continual guidance and support. Deborah and Lynsey's survey volunteers deserve recognition and thanks for their commitment. Erik Paterson deserves special mention for providing survey training vital to Lynsey's application for a great crested newt species licence. Dr. Pete Minting also provided survey training in support of this licence application. Froglife generously provided torches for torchlight surveys in this study. Finally, Prof. Dan Hayden and Robert Paton assisted in resolution of modeling issues and construction of $\mathrm{R}$ code.

Open Access This article is distributed under the terms of the Creative Commons Attribution 4.0 International License (http:// creativecommons.org/licenses/by/4.0/), which permits unrestricted use, distribution, and reproduction in any medium, provided you give appropriate credit to the original author(s) and the source, provide a link to the Creative Commons license, and indicate if changes were made. 


\section{References}

ARG-UK, 2008. ARG-UK Advice Note 4: Amphibian disease precautions: a guidance for UK fieldworkers, version 1: February 2008. Amphibian and Reptile Groups of the United Kingdom.

ARG-UK, 2010. ARG-UK Advice Note 5: Great Crested Newt Habitat Suitability Index, May 2010. Amphibian and Reptile Groups of the United Kingdom.

Akaike, H., 1973. Maximum likelihood identification of Gaussian autoregressive moving average models. Biometrika 60: 255-265.

Baker, J., T. Beebee, J. Buckley, A. Gent \& D. Orchard, 2011. Amphibian Habitat Management Handbook. Amphibian and Reptile Conservation, Bournemouth.

Bates, D., M. Maechler, B. Bolker \& S. Walker, 2015. lme4: linear mixed-effects models using Eigen and S4. Journal of Statistical Software 67: 1-48.

Beebee, T. J. C., 1985. Discriminant analysis of amphibian habitat determinants in South-East England. AmphibiaReptilia 6: 35-43.

Beebee, T., 2015. The great crested newt: an ongoing conservation dilemma. British Wildlife 26: 230-236.

Beebee, T. J. \& R. A. Griffiths, 2005. The amphibian decline crisis: a watershed for conservation biology? Biological Conservation 125: 271-285.

Booth, G. D., M. J. Niccolucci \& E. G. Schuster, 1994. Identifying proxy sets in multiple linear regression: an aid to better coefficient interpretation. Research paper INT (USA).

Bowler, D. E., C. Hof, P. Haase, I. Kröncke, O. Schweiger, R. Adrian, L. Baert, H.-G. Bauer, T. Blick, R. W. Brooker, W. Dekoninck, S. Domisch, R. Eckmann, F. Hendrickx, T. Hickler, S. Klotz, A. Kraberg, I. Kühn, S. Matesanz, A. Meschede, H. Neumann, R. O'Hara, D. J. Russell, A. F. Sell, M. Sonnewald, S. Stoll, A. Sundermann, O. Tackenberg, M. Türkay, F. Valladares, K. van Herk, R. van Klink, R. Vermeulen, K. Voigtländer, R. Wagner, E. Welk, M. Wiemers, K. H. Wiltshire \& K. Böhning-Gaese, 2017. Cross-realm assessment of climate change impacts on species' abundance trends. Nature Ecology \& Evolution 1: 0067.

Butchart, S. H. M., M. Walpole, B. Collen, A. van Strien, J. P. W. Scharlemann, R. E. A. Almond, J. E. M. Baillie, B. Bomhard, C. Brown, J. Bruno, K. E. Carpenter, G. M. Carr, J. Chanson, A. M. Chenery, J. Csirke, N. C. Davidson, F. Dentener, M. Foster, A. Galli, J. N. Galloway, P. Genovesi, R. D. Gregory, M. Hockings, V. Kapos, J.-F. Lamarque, F. Leverington, J. Loh, M. A. McGeoch, L. McRae, A. Minasyan, M. Hernández Morcillo, T. E. E. Oldfield, D. Pauly, S. Quader, C. Revenga, J. R. Sauer, B. Skolnik, D. Spear, D. Stanwell-Smith, S. N. Stuart, A. Symes, M. Tierney, T. D. Tyrrell, J.-C. Vié \& R. Watson, 2010. Global biodiversity: indicators of recent declines. Science 328 : 1164-1168.

Deeming, D. C., 2008. Capture of smooth newts (Lissotriton vulgaris) and great crested newts (Triturus cristatus) correlates with the lunar cycle. Herpetological Journal 18: 171-174.
Denoël, M. \& G. F. Ficetola, 2008. Conservation of newt guilds in an agricultural landscape of Belgium: the importance of aquatic and terrestrial habitats. Aquatic Conservation: Marine and Freshwater Ecosystems 18: 714-728.

Denoël, M., A. Perez, Y. Cornet \& G. F. Ficetola, 2013. Similar local and landscape processes affect both a common and a rare newt species. PLoS ONE 8: e62727.

Duff, J. P., K. Colvile, J. Foster \& N. Dumphreys, 2011. Mass mortality of great crested newts (Triturus cristatus) on ground treated with road salt. Veterinary Record 168: 282.

Edgar, P. W., R. A. Griffiths \& J. P. Foster, 2005. Evaluation of translocation as a tool for mitigating development threats to great crested newts (Triturus cristatus) in England, 1990-2001. Biological Conservation 122: 45-52.

Edgar, P. \& D. R. Bird, 2006. Action plan for the conservation of the crested newt Triturus cristatus species complex in Europe. Council of the European Union, Strasbourg: 1-33.

English Nature, 2001. Great Crested Newt Mitigation Guidelines. English Nature, Peterborough.

Ficetola, G. F. \& F. De Bernardi, 2004. Amphibians in a humandominated landscape: the community structure is related to habitat features and isolation. Biological Conservation 119: 219-230.

Fox, J. \& S. Weisberg, 2011. An R Companion to Applied Regression, 2nd ed. Sage, Thousand Oaks.

Gent, T., 2001. The conservation of the great crested newt Triturus cristatus in the UK. Rana 4: 295-305.

Gent, A. H. \& S. D. Gibson, 1998. Herpetofauna Workers' Manual. Joint Nature Conservation Committee, Peterborough.

Grant, R. A., E. A. Chadwick \& T. Halliday, 2009. The lunar cycle: a cue for amphibian reproductive phenology? Animal Behaviour 78: 349-357.

Grant, R., T. Halliday \& E. Chadwick, 2012. Amphibians' response to the lunar synodic cycle-a review of current knowledge, recommendations, and implications for conservation. Behavioral Ecology 24: 53-62.

Griffiths, R. A. \& H. Inns, 1998. Herpetofauna Workers' Manual. Joint Nature Conservation Committee, Peterborough.

Gustafson, D. H., A. S. L. Andersen, G. Mikusińsk \& J. C. Malmgren, 2009. Pond quality determinants of occurrence patterns of great crested newts (Triturus cristatus). Journal of Herpetology 43: 300-310.

Gustafson, D. H., J. C. Malmgren \& G. Mikusiński, 2011. Terrestrial habitat predicts use of aquatic habitat for breeding purposes - a study on the great crested newt (Triturus cristatus). Annales Zoologici Fennici 48: 295-307.

Harper, L. R., D. C. McNeill \& J. R. Downie, 2017. The latest chapter in a conservation story: completing 10 years of post-translocation monitoring for a population of great crested newt (Triturus cristatus) in Scotland. The Glasgow Naturalist 26: 29-44.

Harrison, X. A., 2014. Using observation-level random effects to model overdispersion in count data in ecology and evolution. PeerJ 2: e616.

Hartel, T., S. Nemes \& K. Oellerer, 2010. Using connectivity metrics and niche modelling to explore the occurrence of the northern crested newt Triturus cristatus (Amphibia, Caudata) in a traditionally managed landscape. Environmental Conservation 37: 195-200. 
Haubrock, P. J. \& J. Altrichter, 2016. Northern crested newt (Triturus cristatus) migration in a nature reserve: multiple incidents of breeding season displacements exceeding $1 \mathrm{~km}$. The Herpetological Bulletin 138: 31-33.

Hervé, M., 2015. RVAideMemoire: Diverse Basic Statistical and Graphical Functions. R package version 0.9-69. http:// CRAN.R-project.org/package=RVAideMemoire.

Howard, S. D. \& D. P. Bickford, 2014. Amphibians over the edge: silent extinction risk of data deficient species. Diversity \& Distributions 20: 837-846.

Joly, P., C. Miaud, A. Lehmann \& O. Grolet, 2001. Habitat matrix effects on pond occupancy in newts. Conservation Biology 15: 239-248.

Kröpfli, M., P. Heer \& J. Pellet, 2010. Cost-effectiveness of two monitoring strategies for the great crested newt (Triturus cristatus). Amphibia-Reptilia 31: 403-410.

Kusano, T., T. Miura, S. Terui \& K. Maruyama, 2015. Factors affecting the breeding activity of the Japanese common toad, Bufo japonicus formosus (Amphibia: Bufonidae) with special reference to the lunar cycle. Current Herpetology 34: 101-111.

Langton, T. E. S., C. L. Beckett \& J. P. Foster, 2001. Great Crested Newt Conservation Handbook. Froglife, Halesworth.

Lele, S. R., J. L. Keim \& P. Solymos, 2014. ResourceSelection: Resource Selection (Probability) Functions for UseAvailability Data. R package version 0.3-2. https://CRAN. R-project.org/package=ResourceSelection.

Lewis, B., R. A. Griffiths \& J. W. Wilkinson, 2017. Population status of great crested newts (Triturus cristatus) at sites subjected to development mitigation. Herpetological Journal 27: 133-142.

Matos, C., S. Petrovan, I. A. Ward \& P. Wheeler, 2017. Facilitating permeability of landscapes impacted by roads for protected amphibians: patterns of movement for the great crested newt. PeerJ 5: e2922.

Macgregor, H., 1995. Crested newts-ancient survivors. British Wildlife 7: 1-8.

Maletzky, A., M. Kyek \& A. Goldschmid, 2007. Monitoring status, habitat features and amphibian species richness of crested newt (Triturus cristatus superspecies) ponds at the edge of the species range (Salzburg, Austria). Annales de Limnologie 43: 107-115.

McCulloch, C. E. \& S. R. Searle, 2001. Generalised linear mixed models. Generalized, Linear, and Mixed Models. Wiley, New York: 220-246.

McKinnell, J. M., D. O’Brien, T. Seymour \& T. Gent, 2015. Great crested newt. Version 1.0. In Gaywood, M. J., P. J. Boon, D. B. A. Thompson \& I. M. Strachan (eds), The Species Action Framework Handbook. Scottish Natural Heritage. Battleby, Perth.

McLee, A. G. \& R. W. Scaife, 1992. The colonisation by great crested newts (Triturus cristatus) of a water body following treatment with a piscicide to remove a large population of sticklebacks (Gasterosteus aculeatus). British Herpetological Society Bulletin 42: 6-9.

McNeill, D. C., 2010. Translocation of a population of great crested newts (Triturus cristatus): a Scottish case study. $\mathrm{PhD}$ thesis, University of Glasgow, Glasgow.
McNeill, D. C., J. R. Downie \& B. Ross, 2012. Gartcosh great crested newts: the story so far. The Glasgow Naturalist 25: 87-91.

Miró, A., D. O’Brien, J. Hall \& R. Jehle, 2016. Habitat requirements and conservation needs of peripheral populations: the case of the great crested newt (Triturus cristatus) in the Scottish Highlands. Hydrobiologia 792: 169-181.

Neter, J., W. Wasserman \& M. H. Kutner, 1990. Applied Linear Statistical Models. Irwin, New York.

O'Brien, C. D., J. E. Hall, D. Orchard, C. D. Barratt, J. W. Arntzen \& R. Jehle, 2015. Extending the natural range of a declining species: genetic evidence for native great crested newt (Triturus cristatus) populations in the Scottish Highlands. European Journal of Wildlife Research 61: 27-33.

O’Brien, D., 2016. Great crested newt. In McInerny, C. J. \& P. J. Minting (eds), The Amphibians and Reptiles of Scotland. The Glasgow Natural History Society, Glasgow: 102-117.

O’Brien, D., J. Hall, A. Miró \& J. Wilkinson, 2017. Testing the validity of a commonly-used habitat suitability index at the edge of a species' range: great crested newt Triturus cristatus in Scotland. Amphibia-Reptilia 38: 265-273.

Oldham, R. S., J. Keeble, M. J. S. Swan \& M. Jeffcote, 2000. Evaluating the suitability of habitat for the great crested newt (Triturus cristatus). Herpetological Journal 10: 143-155.

Paterson, E., 2018. Changes in relative population size detection rates of great crested newts (Triturus cristatus) over time. Herpetological Bulletin 143: 12-17.

Pinheiro, J. C. \& D. M. Bates, 2000. Mixed-effects in S and S-Plus. Springer, New York.

R Core Team, 2017. R: A language and environment for statistical computing. R Foundation for Statistical Computing, Vienna, Austria. http://www.R-project.org/.

Rannap, R. \& L. Briggs, 2006. The characteristics of great crested newt Triturus cristatus' breeding ponds. Project Report: Protection of Triturus cristatus in the Eastern Baltic region, LIFE2004NAT/EE/000070, Action A1.

Sala, O. E., F. S. Chapin III, J. J. Armesto, E. Berlow, J. Bloomfield, R. Dirzo, E. Huber-Sanwald, L. F. Huenneke, R. B. Jackson, A. Kinzig, R. Leemans, D. M. Lodge, H. A. Mooney, M. Oesterheld, N. L. Poff, M. T. Sykes, B. H. Walker, M. Walker \& D. H. Wall, 2000. Global biodiversity scenarios for the year 2100. Science 287: 1770-1774.

Sewell, D., R. A. Griffiths, T. J. Beebee, J. Foster \& J. W. Wilkinson, 2013. Survey Protocols for the British Herpetofauna Version 1.0. Amphibian and Reptile Conservation, Bournemouth.

Skei, J. K., D. Dolmen, L. Rønning \& T. H. Ringsby, 2006. Habitat use during the aquatic phase of the newts Triturus vulgaris (L.) and T. cristatus (Laurenti) in central Norway: proposition for a conservation and monitoring area. Amphibia-Reptilia 27: 309-324.

Stuart, S. N., J. S. Chanson, N. A. Cox, B. E. Young, A. S. L. Rodrigues, D. L. Fischman \& R. W. Waller, 2004. Status and trends of amphibian declines and extinctions worldwide. Science 306: 1783-1786. 
Stumpel, A. H. P. \& H. van der Voet, 1998. Characterizing the suitability of new ponds for amphibians. Amphibia-Reptilia 19: 125-142.

Therneau, T., B. Atkinson \& B. Ripley, 2017. rpart: Recursive Partitioning and Regression Trees. R package version 4.112.

Unglaub, B., S. Steinfartz, A. Drechsler \& B. R. Schmidt, 2015. Linking habitat suitability to demography in a pondbreeding amphibian. Frontiers in Zoology 12: 1-10.

Vignoli, L. \& L. Luiselli, 2013. Better in the dark: two Mediterranean amphibians synchronize reproduction with moonlit nights. Web Ecology 13: 1-11.
Vignoli, L., M. D’Amen, F. Della Rocca, M. A. Bologna \& L. Luiselli, 2014. Contrasted influences of moon phases on the reproduction and movement patterns of four amphibian species inhabiting different habitats in central Italy. Amphibia-Reptilia 35: 247-254.

Vuorio, V., R. K. Heikkinen \& O.-P. Tikkanen, 2013. Breeding success of the threatened great crested newt in Boreal Forest Ponds. Annales Zoologici Fennici 50: 158-169.

Wickham, H., 2009. ggplot2: Elegant Graphics for Data Analysis. Springer, New York.

Zuur, A. F., E. N. Ieno, N. Walker, A. A. Saveliev \& G. M. Smith, 2009. Mixed Effects Models and Extensions in Ecology with R. Springer, New York. 